\title{
Komparasi Efektivitas Tiga Tipe Starter Generator yang Digunakan pada Engine Pesawat ATR
}

\author{
Muhammad Andi Nova ${ }^{1 *}$, Lalu Giat Juangsa Putra ${ }^{1)}$, Zakki Fuadi Emzain ${ }^{2)}$ \\ 1) Teknik Perawatan Pesawat Udara, Politeknik Negeri Batam, Batam \\ 2) Teknik Mesin, Politeknik Negeri Malang, Malang \\ * email: andinova@polibatam.ac.id
}

\begin{abstract}
A starter generator (DC generator) is a DC machine that acts as a motor when starting the engine and will become a DC generator when it reaches a certain speed. The DC Starter Generator will function as a starter mode when the speed is $<45 \% \mathrm{NH}$ and will become a DC generator mode when the speed is $>61.5 \%$. There are several types of starter generators on ATR aircraft: 8260-121, 8260-123, and 8260-124. The uses and functions of the three types are the same, but the maintenance schedule intervals are different. Therefore, the purpose of this study was to determine the planned maintenance intervals (brush change, bearing change, and overhaul) and the causes of differences in maintenance intervals for the starter generator. The type of research used is comparative research, where this research compares several parameters related to the planned maintenance of the Starter Generator, which will be operated within 10,000 FH. The results of the treatment intervals obtained are that types 8260121 and 8260-123 each will require 16 times maintenance, while types 8260-124 only need 8 times maintenance. The difference in the number of treatments being less in the 8260-124 type is due to the modification of the brush. In addition, the type 8260-124 has also used a new technology commutator. Therefore, this type is superior to the other two because it can save operational aircraft costs.
\end{abstract}

Keywords - DC generator, ATR aircraft, maintenance shedule

\section{Pendahuluan}

Pesawat ATR merupakan pesawat yang sering digunakan untuk kebutuhan jarak pendek di mana pesawat ini merupakan jenis twin-turboprop yang dikembangkan dan diproduksi di Prancis dan Italia oleh produsen pesawat ATR (Aerei da Tranporto Regionalle or Avions de Transport Regiona) [1]. Di Indonesia, penggunaan pesawat ATR banyak dioperasikan untuk penerbangan perintis di mana pesawat ini tidak membutuhkan runway yang panjang seperti pesawat penumpang bermesin jet. Sistem kelistrikan pada pesawat ATR terdiri dari tiga jenis yaitu arus searah atau direct current $(D C) 28$ Volt $D C$, arus bolak balik atau alternating current dengan constant frequency (AC) 115 Volt AC/400 Hz, dan alternating current dengan variable frequency (ACW) 115 Volt AC/341-488 Hz. 


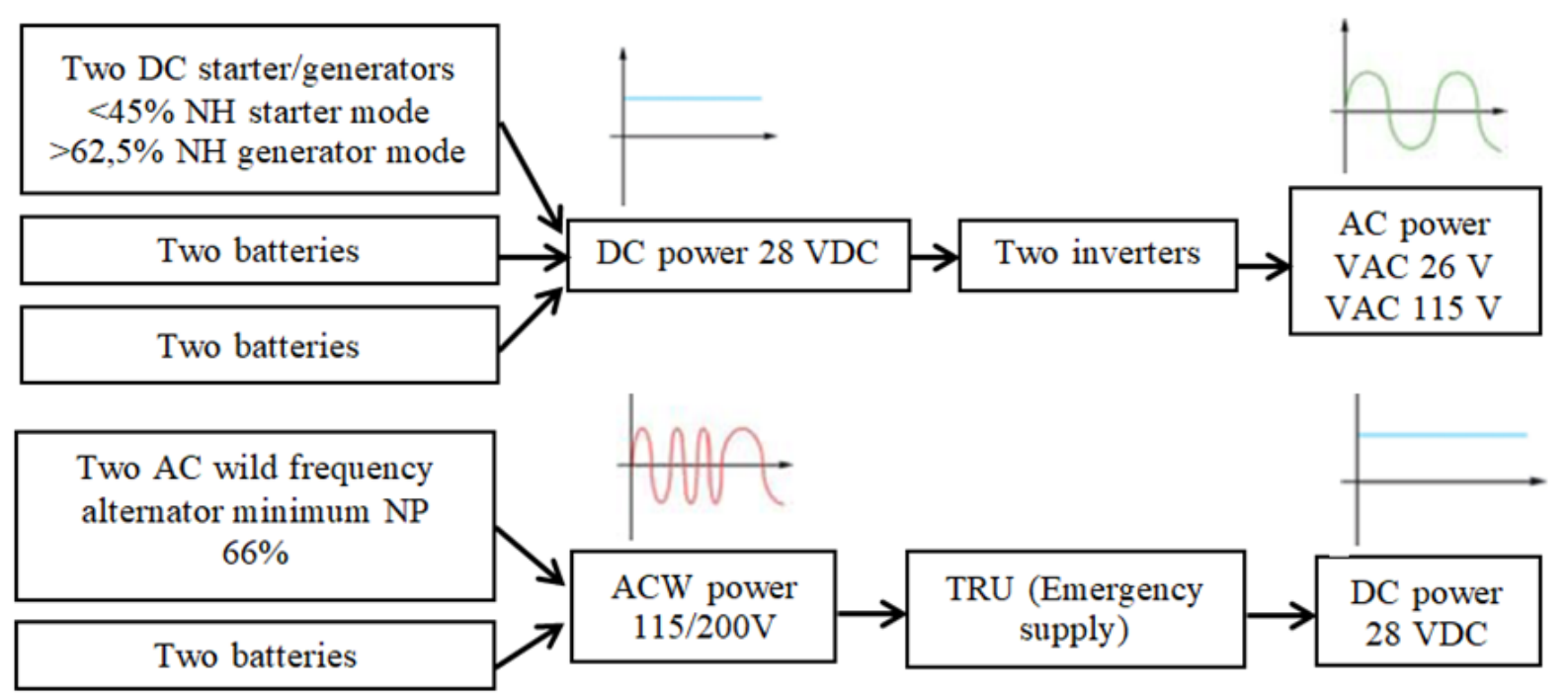

Gambar 1. Sumber kelistrikan pesawat ATR [2]

Sistem elektrikal pada pesawat ATR secara umum dapat dilihat pada Gambar 1 bahwa salah satu sumber kelistrikan pada pesawat ATR adalah Starter Generator (DC generator) atau sering disebut juga dengan Stargen (Starter Generator). Starter Generator adalah sebuah mesin DC yang berperan sebagai motor pada saat menghidupkan engine dan akan menjadi $D C$ generator pada saat mencapai kecepatan tertentu. Fungsi Starter Generator sebagai motor adalah menyediakan tenaga mekanik untuk menghidupkan engine dan fungsinya sebagai generator ialah memasok daya listrik ke pesawat [3]. Starter Generator pada saat kecepatan < $45 \% \mathrm{NH}$ adalah sebagai starter mode dan pada saat $>61,5 \% \mathrm{NH}$ akan menjadi DC generator mode [2].

Mengacu dalam prosedur perawatan, jika dilakukan pembongkaran terhadap komponen Starter Generator, maka harus dilakukan di bawah Maintenance Shop yang mempunyai izin capability jenis part number tersebut. Jenis perawatan terjadwal Starter Generator yang biasanya dilakukan di Maintenance Shop adalah Brush Change, Bearing Change dan Overhaul. Masing-masing tipe part number harus mengikuti panduan perawatan sesuai dengan nomor Component Maintenace Manual (CMM) yang telah ditentukan oleh OEM (Original Equipment Manufacturer). Pada pesawat ATR tipe part number untuk Starter Generator yang digunakan diantaranya adalah part number 8260-121, 8260-123, dan 8260-124 [4-6]. Dalam jadwal perawatan, masing-masing part number telah dicantumkan dalam Maintenance Pogram (MP) bahwa terkait umur Starter Generator harus dilepas di pesawat untuk dilakukan perawatan. Panduan jadwal maintenance wajib diikuti oleh Engineer dalam mangontrol perawatan komponen pesawat.

Dalam upaya menuju transportasi udara global yang aman, banyak teknologi sistem pesawat saat ini mengalami perubahan signifikan [7-11]. Dengan perkembangan tersebut, maka kebutuhan jasa perawatan pesawat juga semakin meningkat. Dalam industri penerbangan, MRO (Maintenance Repair and Overhaul) memiliki peran penting dalam pelayanan perawataan pesawat yang salah satunya adalah perawatan komponen. Maintenance Shop/Workshop adalah perawatan komponen pesawat yang umumnya mempunyai capability untuk inspection, repair, dan overhaul.

Penelitian yang berkaitan DC Starter Generator telah dilakukan sebelumyaa oleh beberapa peneliti lain. Pada penelitian [12] memaparkan mengenai Starter Generator pada saat proses perawatan. Penelitian tersebut berfokus terhadap alur dan instrumen pada saat melakukan perawatan mulai dari dissambly, cleaning, check/inspeksi, dan assembly. Penelitian 
lainnya adalah [13] membahas terjadinya low voltage yang dihasilkan oleh Starter Generator yang disebabkan karena faktor Brush yang di bawah batas ukuran ketentuan dalam CMM.

Oleh karena itu, pada penelitian ini akan dibahas komparasi beberapa tipe part number untuk Starter Generator. Perlu diketahui bahwa ada beberapa tipe part number yang digunakan pada Pesawat ATR di mana secara fisik mempunyai kesamaan, tapi secara part number mempunyai perbedaan. Masing-masing part number memiliki prosedur tersendiri dalam jadwal perawatan. Dari perbedaan jadwal perawatan, maka akan dicarikan faktor penyebabnya perbedaan interval tersebut.

Dalam proses pemeliharaan atau perawatan suatu komponen pesawat khususnya dalam hal ini Starter Genarator, maka ada dua jenis yang umumnya dilakukan yaitu perawatan preventive dan perawatan korektif. Perawatan preventif merupakan perawatan dalam mencegah suatu kegagalan terhadap Starter Generator sebelum Starter Generator mengalami kerusakan atau kegagalan. Perawatan korektif (condition monitoring) merupakan perawatan atau perbaikan terhadap Starter Generator agar dapat digunakan kembali seperti fungsi semula setelah perbaikan. Untuk Perawatan preventif, perawatan ini dibagi lagi menjadi dua yaitu pertama perawatan periodik (hardtime) di mana perawatan ini merupakan perawatan yang mengacu terhadap batasan umur komponen Starter Generator, dan kedua perawatan oncondition di mana perawatan ini untuk mengetahui kondisi Starter Generator dengan pengecekan/inspeksi dan kemudian dilakukan tindakan.

Tujuan penelitian ini adalah untuk diketahui perbandingan jadwal perawatan Starter Generator khususnya terhadap perawatan terencana (maintenance schedule). Selanjutnya untuk diketahui apa penyebab terjadinya perbedaan interval jadwal perawatan terhadap Starter Generator tipe 8260-121, 8260-123, dan 8260-124 yang dipakai pada pesawat ATR. Jika adanya perbedan interval perawatan, maka otomatis hal ini akan terjadi perbedaan terhadap nilai biaya perawatan.

\section{Metode Penelitian}

Jenis penelitian yang dilakukan merupakan penelitian komparatif, di mana penelitian ini membadingkan kondisi satu variabel atau lebih pada dua atau lebih sampel objek yang berbeda. Objek pada penelitian ini adalah Starter Generator yang memiliki jenis part number yang berbeda yaitu tipe 8260-121, 8260-123, dan 8260-124. Dalam kasus ini akan dilakukan komparasi terhadap beberapa parameter yang berkaitan dengan jadwal perawatan terencana Starter Generator yaitu Brush Change, Bearing Change, dan Overhaul. Mengacu ke jadwal perawatan tersebut, selanjutnya dilakukan komparasi terhadap jumlah perawatan Starter Generator apabila akan dioperasikan pada pesawat selama 10.000 FH. Dari jumlah interval perawatan masing-masing tipe Starter Generator yang didapatkan, maka akan diketahui seberapa besar efektifitas dari ke tiga Starter Generator tersebut. Pada penelitian ini juga akan diketahui apa penyebab dari ketiga tipe Starter Generator tersebut terjadi perbedaan interval dalam perawatan khusunya terhadap perawatan terencana yaitu brush change, bearing change, dan overhaul.

\section{Hasil dan Pembahasan}

Perawatan terencana Starter Generator pesawat ATR mengikuti prosedur Maintenance Pogram (MP) terkait umur komponen untuk dilakukan perawatan baik itu brush change, bearing change, dan overhaul. Perawatan Starter Generator tipe part number 8260-121 dan 8260-123 secara umum mempunyai kesamaan jadwal interval perawatan, sedangkan tipe 8260124 memiliki interval perawatan yang berbeda. Tipe 8260-121 dan 8260-123 pada saat dilakukan perawatan di Maintenance Shop ada kebutuhan untuk pergantian kit komponen baik pada saat brush change, bearing change, ataupun overhaul di mana masing-masing memiliki 
part number kit yang berbeda. Dari kegunaan dan fungsi kit komponennya sama, tapi perbedaan part number kit tersebut ditentukan dalam Component Maintenance Manual (CMM) dan wajib untuk diikuti. Sedangkan untuk jenis Starter Generator tipe 8260-124 di mana memiliki perbedaan signifikan terhadap interval perawatan terencana dibandingkan dengan Starter Generator 8260-121 dan 8260-123.

Beberapa perawatan terencana Starter Generator yang dilakukan yaitu brush change, bearing change, dan overhaul, di mana perawatannya dilakukan pada saat mencapai Flight Hours (FH) yang telah ditentukan untuk masing-masing tipe part number Starter Generator. Overhaul merupakan perawatan besar terhadap Starter Generator dengan banyak komponen yang harus diganti termasuk juga pengerjaan terhadap pergantian brush dan bearing di dalamnya.

Data informasi di lapangan bahwa perawatan terjadwal Starter Generator yang dilakukan di Maintenance Shop untuk masing-masing tipe Starter Generator adalah sebagai berikut.

a) Tipe $8260-121$

Pada starter generator tipe ini umumnya brush change dilakukan pada saat jamnya mencapai 600 FH di mana FH brush ini dihitung dari saat setelah terpasang di Starter Generator. Sebelum mencapai angka $600 \mathrm{FH}$, brush ini dianjurkan untuk dilakukan pengecekan pada tiap $500 \mathrm{FH}$. Apabila hasil pengecekan semua brush kondisinya adalah green atau kondisi masih dalam kategori batasan yang ditentukan, maka Starter Generator masih dapat digunakan sampai ke tahap jadwal maintenance yaitu sampai total jamnya mencapai 600 FH. Selanjutnya, bearing change dilakukan setiap mencapai pemakaian 1200 FH. Jika brush dan bearing memiliki permasalahan atau kerusakan pada saat belum mencapai jam tersebut, maka Starter Generator dilakukan perawatan tidak terencana. Sedangkan untuk kegiatan Overhaul, ini akan dilakukan pada saat Starter Generator tiap mencapai 2400 FH.

b) Tipe $8260-123$

Jenis starter generator tipe ini hampir sama dengan maintenance pada tipe 8260-121. Brush Change dilakukan pada saat jamnya sekitar $600 \mathrm{FH}$ dihitung dari saat terpasang pada Starter Generator. Sebenarnya Starter Generator tipe part number ini mampu mencapai sampai $800 \mathrm{FH}$ untuk dilakukan brush change. Dengan adanya regulasi dari OEM dan faktor pertimbangan dari jadwal bearing change maka saat ini dilakukan brush change di saat tiap mencapai 600 FH. Bearing change dilakukan setiap pemakaian bearing pada Starter Generator mencapai 1200 FH. Sedangkan untuk jadwal perawatan overhaul pada Starter Generator tipe ini adalah $2400 \mathrm{FH}$.

c) Tipe $8260-124$

Secara garis besar, jadwal maintenance untuk tipe ini sangat berbeda dengan dua tipe yang dijelaskan sebelumnya. Pada part number tipe ini dilakukan brush and bearing change (BBC) tiap brush dan bearing mencapai $1200 \mathrm{FH}$, di mana perhitungannya adalah pada saat setelah brush dan bearing terpasang di Starter Generator. Jadwal perawatan untuk overhaul pada tipe ini adalah pada saat mencapai $3600 \mathrm{FH}$.

Dengan adanya data informasi perawatan terencana pada Maintenance Shop untuk tiap tipe Starter Generator ini, maka ketiga tipe tersebut akan diketahui seperti apa interval perawatan apabila Starter Generator dilakukan instalasi pada pesawat yang akan dioperasikan selama 10.000 FH. Jika tiap tipe Starter Generator dioperasikan selama $10.000 \mathrm{FH}$ pada pesawat, maka interval maintenance yang harus dilakukan dapat dilihat seperti pada Table 1 . 
Tabel 1. Jadwal perawatan starter generator ATR

\begin{tabular}{c|c|c|c}
\hline $\begin{array}{c}\text { Flight } \\
\text { hours }\end{array}$ & $\begin{array}{c}\text { Maintenance } \\
\mathbf{8 2 6 0 - 1 2 1}\end{array}$ & $\begin{array}{c}\text { Maintenance } \\
\mathbf{8 2 6 0 - 1 2 3}\end{array}$ & $\begin{array}{c}\text { Maintenance } \\
\mathbf{8 2 6 0 - 1 2 4}\end{array}$ \\
\hline 0 & Installation & Installation & Installation \\
\hline 600 & Brush change & Brush change & - \\
\hline 1.200 & BBC & BBC & BBC \\
\hline 1.800 & Brush change & Brush change & - \\
\hline 2.400 & Overhaul & Overhaul & BBC \\
\hline 3.000 & Brush change & Brush change & - \\
\hline 3.600 & BBC & BBC & Overhaul \\
\hline 4.200 & Brush change & Brush change & - \\
\hline 4.800 & Overhaul & Overhaul & $B B C$ \\
\hline 5.400 & Brush change & Brush change & - \\
\hline 6.000 & BBC & BBC & $B B C$ \\
\hline 6.600 & Brush change & Brush change & - \\
\hline 7.200 & Overhaul & Overhaul & Overhaul \\
\hline 7.800 & Brush change & Brush change & - \\
\hline 8.400 & BBC & BBC & $B B C$ \\
\hline 9.000 & Brush change & Brush change & - \\
\hline 9.600 & Overhaul & Overhaul & $B B C$ \\
\hline 10.000 & - & - & - \\
\hline
\end{tabular}

Jenis perawatan terencana yang ditampikan pada Tabel 1 yaitu untuk perawatan brush change, bearing change, dan overhaul. Berdasarkan Tabel 1 dapat diketahui bahwa ada perbedaan terhadap salah satu dari tiga tipe Starter Generator tersebut terhadap interval perawatan pada saat dioperasikan selama 10.000 FH. Dari daftar Jadwal Perawatan Starter Generator pesawat ATR maka dapat diketahui jumlah dan perbandingan interval perawatan tiap tipe Starter Generator seperti pada Tabel 2.

Tabel 2. Perbandingan interval perawatan dalam $10.000 \mathrm{FH}$

\begin{tabular}{l|c|c|c}
\hline \multicolumn{1}{c|}{ Jenis Peawatan } & $\mathbf{8 2 6 0 - 1 2 1}$ & $\mathbf{8 2 6 0 - 1 2 3}$ & $\mathbf{8 2 6 0 - 1 2 4}$ \\
\hline Brush Change & $8 \mathrm{kali}$ & $8 \mathrm{kali}$ & - \\
\hline BBC & $4 \mathrm{kali}$ & $4 \mathrm{kali}$ & $6 \mathrm{kali}$ \\
\hline Overhaul & $4 \mathrm{kali}$ & $4 \mathrm{kali}$ & $2 \mathrm{kali}$ \\
\hline Total Perawatan & 16 & 16 & 8 \\
\hline
\end{tabular}

Berdasarkan Jumlah perawatan terhadap ketiga tipe Starter Generator maka tipe 8260124 memiliki jumlah perawatan yang lebih sedikit yaitu total 8 kali perawatan terencana, sedangkan untuk tipe 8260-121 dan 8260-121 masing-masing 16 kali perawatan dalam kurun waktu 10.000 FH. Perawatan per unit Starter Generator lebih jelas untuk perbedaan jumlah perawatannya dapat dilihat pada Gambar 2. Tipe 8260-124 tidak ada kategori perawatan brush change (tiap mencapai $600 \mathrm{FH}$ ) seperti pada dua tipe lainnya. Brush pada tipe 8260-124 mampu bertahan sampai mencapai 1.200 FH yaitu sampai jadwal perawatan kategori BBC. Starter generator tipe ini hanya dilakukan dua perawatan terencana yaitu $\mathrm{BBC}$ dan overhaul. 


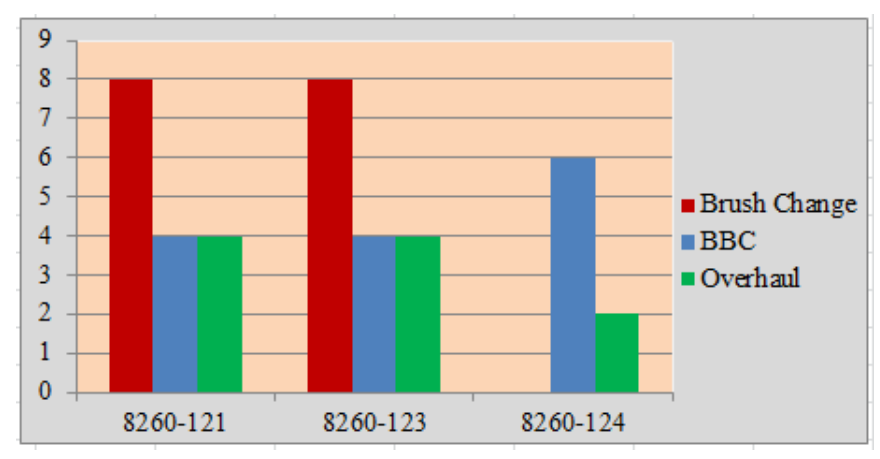

Gambar 2. Jumlah perawatan terencana per tipe (dalam 10.000 FH)

Dari hasil pengamatan, faktor perbedaan interval perawatan ini dikarenakan adanya perbedaan ketebalan brush yang dimiliki oleh tipe 8260-124, di mana mempunyai nilai ketebalan $43 \mathrm{~mm}$. Brush ini merupakan modifikasi dari brush yang digunakan pada kedua tipe 8260-121 dan 8260-121. Selain perbedaan dari modifikasi brush, ada beberapa bagian lain yang ditingkatkan oleh OEM yaitu pemakaian kommutator berteknologi baru pada tipe 8260124 dan desain spring yang menyesuaikan dengan kebutuhan brush. Keunggulan yang miliki oleh tipe 8260-124 akan memberi dampak positif terhadap penghematan biaya perawatan pesawat. Semakin sedikit jumlah perawatan terencana, maka efektifitas yang dimiliki oleh Starter Generator semakin tinggi. Sebaliknya, semakin banyak jumlah perawatan terencana, maka efektifitas yang dimiliki semakin rendah. Oleh karena itu, dengan sedikitnya jumlah perawatan maka dapat dilakukannya penghematan biaya operational pesawat.

\section{Kesimpulan}

Ada beberapa tipe part number untuk Starter Generator yang digunakan pesawat ATR diantara adalah 8260-121, 8260-123, dan 8260-124. Jenis perawatan terencana Starter Generator yaitu brush change, bearing change, dan overhaul. Berdasarkan jadwal perawatan terencana, apabila masing-masing tipe Starter Generator tersebut dioperasikan pada pesawat selama $10.000 \mathrm{FH}$, maka didapatkan nilai interval dan jumlah perawatannya. Part number 8260-121 dan 8260-123 masing-nasing memiliki 16 kali perawatan, sedangkan tipe part number 8260-124 hanya memiliki 8 kali perawatan. Faktor penyebab terjadinya perbedaan interval dan jumlah perawatan dikarenakan ketebalasan brush yang dimiliki oleh tipe 8260124 mempunyai nilai ketebalan 43mm, di mana brush ini merupakan modifikasi dari brush yang digunakan kedua tipe 8260-121 dan 8260-121. Perbedaan pendukung lainnya adalah kommutator yang digunakan adalah kommutator berteknologi baru dan spring juga disuaikan dengan kebutuhan brush. Jika dibandingkan dua tipe lainnya, maka keunggulan yang dimiliki oleh Starter Generator 8260-124 dapat menghemat biaya perawatan komponen sehingga akan mengurangi biaya operational pesawat.

\section{Daftar Pustaka}

[1] Bajaj, A. S. (2019). Development of Flight Envelope of a Twin Turboprop Aircraft (ATR-72).

[2] Training and Flight Operations Support Team. (2010). ATR Training and Flight Operation Services. SYSTEM ATR.

[3] Su, W. C., Hwang, M. S., \& Lin, C. F. (2001). Aircraft starter/generator control unit design. Journal of the Chinese Institute of Engineers, 24(1), 1-8. 
[4] Thales. (2017). Starter Generator P/N: 8260-121 P/N: 8260-123. Component Maintenance Manual with Illutrated Parts List, 11th ed. Thales Avionics Electrical Systems (SAS).

[5] Thales. (2017). Starter Generator P/N: 8260-124. Component Maintenance Manual with Illutrated Parts List. Thales Avionics Electrical System (SAS).

[6] ATR. (2018). ATR Upgrades Services Catalogue. ATR 42 \& 72 Product \& Services.

[7] Bozhko, S., Yang, T., Le Peuvedic, J. M., Arumugam, P., Degano, M., La Rocca, A., ... \& Wheeler, P. (2018). Development of aircraft electric starter-generator system based on active rectification technology. IEEE Transactions on Transportation Electrification, 4(4), 985-996.

[8] Zhang, Z., Huang, J., Jiang, Y., Geng, W., \& Xu, Y. (2017). Overview and analysis of PM starter/generator for aircraft electrical power systems. CES Transactions on Electrical Machines and Systems, 1(2), 117-131.

[9] Grachev, P. Y., Strizhakova, E. V., \& Tabachinskiy, A. S. (2017, May). Startergenerator design and analysis of start/stop processes for HEVs. In 2017 International Conference on Industrial Engineering, Applications and Manufacturing (ICIEAM) (pp. 1-4). IEEE.

[10] Yeoh, S. S. (2016). Control strategies for the More Electric Aircraft starter-generator electrical power system (Doctoral dissertation, University of Nottingham).

[11] Nøland, J. K., Leandro, M., Suul, J. A., \& Molinas, M. (2020). High-power machines and starter-generator topologies for more electric aircraft: A technology outlook. IEEE Access, 8, 130104-130123.

[12] Firdaus, A. M. (2020). Pemeliharaan DC Starter Generator pada Pesawat ATR 72-600. In Seminar Nasional Teknik Elektro (Vol. 5, No. 1, pp. 71-74).

[13] Fajarudin, I., \& Subijanto, S. (2020). Analisa Terjadinya Low Output Voltage pada Starter Generator Dc pada Pesawat Cn 235 Pk-Hne dan Upaya Penanggulangannya. Jurnal Industri Elektro dan Penerbangan, 4(2). 